\title{
Normal Spleen Size in Relation To Weight of Adult Population in the Northwest Ethiopia Region: A Radiological Study.
}

\author{
Yared Tekle ${ }^{1}$, Sanket Dadarao Hiware ${ }^{2}$, Abebe Muche ${ }^{3}$, ZerubabelTegegne ${ }^{4}$, Hussen Mohammed ${ }^{5}$, Pradeep Bokariya ${ }^{6}$ \\ ${ }^{1}$ Lecturer, Department of Anatomy, College of Medicine and Health Sciences, Dire Dawa University, Dire Dawa, Ethiopia, ${ }^{2}$ Assistant professor, Department of \\ Anatomy, Imam Abdulrahman Bin Faisal University, College of Medicine, Dammam, Saudi Arabia, ${ }^{3}$ Associate Professor, Department of Anatomy, College of \\ Medicine, University of Gondar, Gondar, Ethiopia, ${ }^{4}$ Associate Professor, Department of Radiology, College of Medicine, University of Gondar, Gondar, Ethiopia, \\ ${ }^{5}$ Lecturer, Department of public health, College of Medicine and Health Sciences, Dire Dawa University, Dire Dawa, Ethiopia, ${ }^{6}$ Assistant professor, Department of \\ Anatomy, Mahatma Gandhi Institute of Medical Sciences, Sewagram, India.
}

\section{Abstract}

Background: Ultrasonography is the first imaging method to assess splenomegaly. So far, established normal limits of spleen dimensions remain scanty in the Ethiopian population, and the ultrasound data from the previous studies demonstrated that racial differences could affect the splenic volume; this necessitates the establishment of normative data of spleen dimensions for different areas. Subjects and Methods: A cross-sectional prospective study design was performed at the University of Gondar, hospital. The sonographic measurements of spleen length, width, thickness and volume were performed on 380 subjects. In addition, weight of the subjects were measured using standard anthropometric technique. Age and sex were also recorded. By Pearson's product moment correlation coefficients, the relation of spleen dimensions to weight was evaluated. Results: In males, there is a statistically significant positive correlation between subject weight and spleen length $(\mathrm{r}=0.244, \mathrm{P}<0.001)$, and volume $(\mathrm{r}=0.164, \mathrm{P}<0.05)$; however, there is no statistically significant correlation with spleen width $(\mathrm{r}=0.034, \mathrm{P}>0.05)$ and spleen thickness $(\mathrm{r}=0.136, \mathrm{P}>0.05)$. In females there is a statistically significant positive correlation between the weight of female subject and spleen length $(r=0.274, \mathrm{P}<0.001)$, width $(\mathrm{r}=0.239, \mathrm{P}<0.01)$, thickness $(\mathrm{r}=0.244$, $\mathrm{P}<0.01)$, and volume $(\mathrm{r}=0.335$, $\mathrm{P}<0.0001)$. Conclusion: The positive correlation is found between the spleen parameters and weight of both the genders in Ethiopian population which has both clinical and forensic importance.

Keywords: Spleen dimensions, Weight, Ultra-sonography.

Corresponding Author: Dr. Sanket Dadarao Hiware, Assistant professor, Department of Anatomy, Imam Abdulrahman Bin Faisal University, College of Medicine, Dammam, Saudi Arabia.

Received: December 2018

Accepted: February 2019

\section{Introduction}

The spleen is the largest organ in the reticulo endothelial system. Spleen size is important in the evaluation of gastrointestinal and haematological diseases for both radiologists and clinicians. ${ }^{[1]}$ The normal spleen weighs $150-200 \mathrm{~g}$, and is $10.9 \pm 1.4 \mathrm{~cm}$ long, $4.0 \pm 0.45 \mathrm{~cm}$ deep, and $6.8 \pm 0.71 \mathrm{~cm}$ in diameter. It is located in the left hypogastric quadrant of the abdomen beneath the 9th to the 11 th intercostal spaces. It is a crescent shaped structure, with a convex outer margin, and indented inner margin. ${ }^{[2]}$ Splenomegaly is a well-known manifestation of several diseases that may involve the liver, immune system, and hematopoietic system. The reliability of clinical palpation is imprecise; the normal spleen is usually not palpable, whereas a non-palpable spleen is not always normal sized. ${ }^{[3]}$ The spleen volume can be measured by various techniques such as radiography, scintigraphy, CT, MRI, and ultrasonography. Ultrasonography is the first imaging method to assess splenomegaly. It is a non-invasive, commonly available, and an affordable imaging method without the risk of ionizing radiation. ${ }^{[4]}$

Current knowledge of spleen size is based on different populations or derived from autopsy studies. ${ }^{[5-8]}$ So far, established normal limits of spleen dimensions remain scanty in the Ethiopian population, and the ultrasound data from the previous studies demonstrated that racial differences could affect the splenic volume; this necessitates the establishment of normative data of spleen dimensions for different areas.

The aim of this prospective screening survey was to establish reference values of splenic dimensions and volume in a population of adult healthy Ethiopians, and to determine the relationship of splenic volume with weight. This study was conducted as a first step in an attempt to improve the study design prior to performance of a full scale investigation of splenic volumes in this population.

\section{Subjects and Methods}

The study was performed at the Radiology and Anatomy Departments, University of Gondar Referral Hospital, 
Northwest Ethiopia. 380 adult subjects (180 males and 200 females) were included in this study, and written informed consent was taken for each case. Ethical approval was obtained from the Academic Research Council of the University.

\section{Exclusion criteria}

a) History of any previous or current conditions that might involve the size of the spleen.

b) Clinical or laboratory evidence of infection (subjects who had fever either at the time of the examination or within at least 4 weeks prior to the examination)

c) Hematopoietic diseases

d) Genetic diseases (thalassemia and sickle cell anaemia)

e) Lymphadenopathy

f) Liver diseases (cirrhosis or portal hypertension)

g) Renal failure

h) History of splenic trauma

i) Non-traumatic benign splenic lesions (infarctions, lobulations, cysts, accessory spleen, and haemangioma)

j) Malignant lesions

k) Pregnancy.

Following radiological parameters were measured

Spleen length: Measured in longitudinal plane at hilum the maximum distance between the dome of the spleen and the splenic tip. ${ }^{[5]}$

Spleen width: Measured in a plane perpendicular to the length at hilum the maximum distance between the medial and lateral borders of the spleen. ${ }^{[5]}$

Spleen thickness: The maximum AP dimension measured on the transverse section. ${ }^{[5]}$

Volume of the spleen: length $\times$ width $\times$ depth $\times 0.524)$ [8] (The formula is frequently used for estimation of the volume of many irregularly shaped organs.)

The patients selected for the present study were examined using a Sonoscape SSI 8000 ultrasound machine (Soonchunhyang University Medical center, China) for abdominal and/or pelvic problems not related to the spleen.

In addition to sonographic data, baseline data including age, gender and weight were recorded for all participants. Weight was measured with the help of weighing machine using standard anthropometric method. ${ }^{[7]}$

The collected data were checked for completeness, accuracy and clarity before analysis. The data were entered into a spreadsheet and analysed using the IBM SPSS Statistics, version 20. The means ( \pm standard deviation), ranges, minimum, maximum, and the $95 \%$ confidence intervals for the mean (in order to include the true population mean in $95 \%$ of the cases) were all calculated. P- Value less than 0.05 is considered as statistically significant. The coronal measurements of the spleen and the volume were compared with the height of the various subjects. Differences of continuous variables between two independent groups were assessed with the 2-tailed t-test. The relationship between splenic dimensions and height was assessed with the Pearson`s correlation coefficient (r).
The splenic parameters (mean \pm standard deviation) is shown in [Figure 1]. A statistically significant difference between males and females was observed in weight $(\mathrm{p}<0.0001)$. The mean weight in males and females is found to be $62.0( \pm 8.3)$ and $53.9( \pm 8.6)$ respectively.

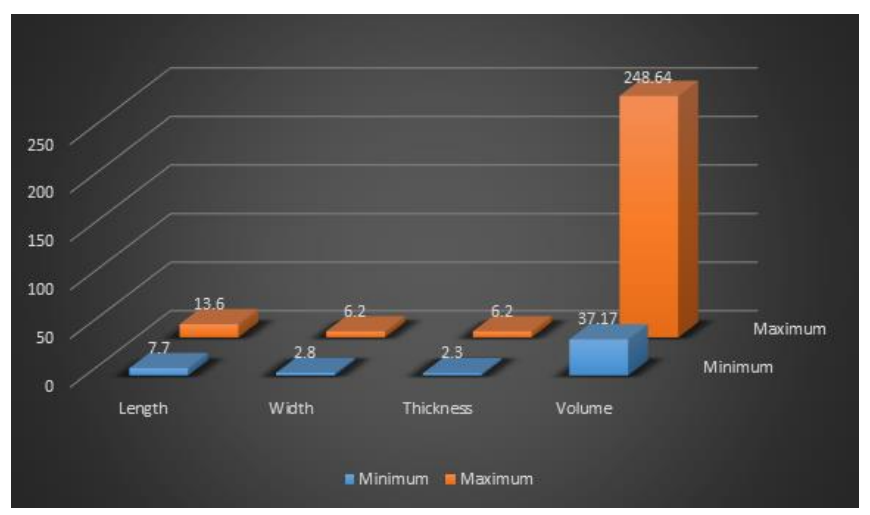

Figure 1: Radiographic range of dimensions of spleen.

Table 1: Pearson's correlation ( $r$ ) of spleen dimension with weight of all study population.

\begin{tabular}{|l|l|l|l|l|l|}
\hline \multicolumn{2}{|c|}{} & $\begin{array}{l}\text { Spleen } \\
\text { length } \\
\text { in cm }\end{array}$ & $\begin{array}{l}\text { Spleen } \\
\text { width } \\
\text { in cm }\end{array}$ & $\begin{array}{l}\text { Spleen } \\
\text { thickness } \\
\text { in cm }\end{array}$ & $\begin{array}{l}\text { Volume } \\
\text { of } \\
\text { spleen } \\
\text { (cm3) }\end{array}$ \\
\hline \multirow{2}{*}{$\begin{array}{l}\text { Weight } \\
\text { In kg }\end{array}$} & $\begin{array}{l}\text { Pearson } \\
\text { Correlation }\end{array}$ & 0.409 & 0.274 & 0.27 & 0.373 \\
\cline { 2 - 6 } & $\begin{array}{l}\text { Sig. (2- } \\
\text { tailed) }\end{array}$ & 0 & 0 & 0 & 0 \\
\cline { 2 - 6 } & $\mathrm{N}$ & 380 & 380 & 380 & 380 \\
\hline
\end{tabular}

Table 2: Pearson's correlation $(r)$ of spleen dimension with weight of male study population.

\begin{tabular}{|l|l|l|l|l|l|}
\hline \multicolumn{2}{|c|}{} & $\begin{array}{l}\text { Spleen } \\
\text { length } \\
\text { in cm }\end{array}$ & $\begin{array}{l}\text { Spleen } \\
\text { width } \\
\text { in cm }\end{array}$ & $\begin{array}{l}\text { Spleen } \\
\text { thickness } \\
\text { in cm }\end{array}$ & $\begin{array}{l}\text { Volume } \\
\text { of } \\
\text { spleen } \\
\text { (cm3) }\end{array}$ \\
\hline \multirow{2}{*}{$\begin{array}{l}\text { Weight } \\
\text { In kg }\end{array}$} & $\begin{array}{l}\text { Pearson } \\
\text { Correlation }\end{array}$ & 0.244 & 0.034 & 0.136 & 0.162 \\
\cline { 2 - 6 } & $\begin{array}{l}\text { Sig. (2- } \\
\text { tailed) }\end{array}$ & 0.001 & 0.646 & 0.069 & 0.029 \\
\cline { 2 - 6 } & $\mathrm{N}$ & 180 & 180 & 180 & 180 \\
\hline
\end{tabular}

Table 3: Pearson's correlation (r) of spleen dimension with weight of female study population.

\begin{tabular}{|l|l|l|l|l|l|}
\hline \multicolumn{2}{|c|}{} & $\begin{array}{l}\text { Spleen } \\
\text { length } \\
\text { in cm }\end{array}$ & $\begin{array}{l}\text { Spleen } \\
\text { width } \\
\text { in cm }\end{array}$ & $\begin{array}{l}\text { Spleen } \\
\text { thickness } \\
\text { in cm }\end{array}$ & $\begin{array}{l}\text { Volume } \\
\text { of } \\
\text { spleen } \\
\text { (cm3) }\end{array}$ \\
\hline \multirow{2}{*}{$\begin{array}{l}\text { Weight } \\
\text { In kg }\end{array}$} & $\begin{array}{l}\text { Pearson } \\
\text { Correlation }\end{array}$ & 0.274 & 0.239 & 0.244 & 0.335 \\
\cline { 2 - 6 } & Sig. (2-tailed) & 0 & 0.001 & 0.001 & 0 \\
\cline { 2 - 6 } & $\mathrm{N}$ & 200 & 200 & 200 & 200 \\
\hline
\end{tabular}

A moderate positive significant correlation $(\mathrm{P}<0.0001)$ was found between the splenic length, width, volume and body weight ( $\mathrm{r}:>0.3)$ [Table 1].

In males, there was a statistically significant positive correlation between subject weight and spleen length $(\mathrm{r}=0.244, \quad \mathrm{P}<0.001)$, and volume $(\mathrm{r}=0.164, \quad \mathrm{P}<0.05)$;

Results 
however, there was no statistically significant correlation with spleen width $(\mathrm{r}=0.034, \mathrm{P}>0.05)$ and spleen thickness $(\mathrm{r}=0.136, \mathrm{P}>0.05)$ [Table 2].

In contrast to this in females there was a statistically significant positive correlation between the weight of female subject and spleen length $(\mathrm{r}=0.274, \mathrm{P}<0.001)$, width $(\mathrm{r}=0.239, \mathrm{P}<0.01)$, thickness $(\mathrm{r}=0.244, \mathrm{P}<0.01)$, and volume $(\mathrm{r}=0.335, \mathrm{P}<0.0001)[$ Table 3$]$.

\section{Discussion}

The wide range of normal spleen size values reported in the literature of different races makes the establishment of normal ranges more difficult. Taking the upper limits readings into consideration, our values were still higher than the data from Indians for example, implicating that ethnicity could be attributed in part to the wide ranges of normative data registered by different populations. ${ }^{[11,12]}$

A recent study performed on Saudi Arabian adults to estimate splenic volume using 3-dimensional abdominal CT scan images, yielded slightly higher measurements than the values recorded in this study. ${ }^{[13]}$ In the latter study, the same ellipsoid formula was used to calculate the spleen volume, the lower values of sonography measurements in the study were most probably due to overlapping ribs or bowel gas. Spleen length at the hilum is considered the most reproducible linear measurement of spleen size. ${ }^{[14]}$ Splenomegaly is considered as moderate if the biggest dimension is $11-20 \mathrm{~cm}$, and severe if the biggest dimension is greater than $20 \mathrm{~cm} \cdot{ }^{[15]}$ However, caution is required in defining splenomegaly in different populations.

Moderate positive relationships between splenic dimensions and weight, BSA were observed; this was similar to the data from spleen sonography and autopsy. ${ }^{[11,12]}$

Different studies showed unmistakable trend for splenic dimensions to increase in parallel with the increase in the body parameters. The body weight and height might show variations in different ethnic origins. In addition, variations in the body fat distribution might also be caused by variations of physical activity, diet, and ethnicity. So the variations of body parameters could be attributed to different splenic measurements in different areas. Previous studies showed that the longitudinal measurements of the spleen were best correlated only with body height. ${ }^{[16,17]}$ On the other hand, studies of African adults and Turkish males found positive correlation between spleen parameters and body weight. ${ }^{[11,12]}$ From a physiological perspective, our findings would make more sense; as patients with a bigger body habitus will have a larger blood volume requiring larger spleens for filtration.

We believe that the results of this study can be used as a practical and comprehensive guide to indicate the normal spleen length range for the population of Northwest Ethiopa, according to his/ her body habitus and weight.

\section{Limitation of the study}

The main limitation was the small sample size, which certainly has affected the generalizability of our estimates.
A larger study sample is required in order to improve the accuracy of our measurements. Therefore, further studies are needed with larger study populations and more ethnic backgrounds to explore wider environmental and genetic influences that might determine the splenic parameters.

\section{Conclusion}

Pearson`s correlation finding indicated a moderate positive significant correlation $(\mathrm{P}<0.0001)$ between the splenic length, width, volume and body height of all the subjects (r: $>0.3$ ).

No statistically significant correlation with splenic dimensions in males $(r=0.107,0.039,0.060$, and 0.091 for spleen length, width, thickness, and volume, respectively) was found.

Height of female study subjects had a statistically significant positive correlation with spleen length $(\mathrm{r}=0.203$, $\mathrm{P}<0.01)$, width $(\mathrm{r}=0.175, \mathrm{P}<0.05)$, thickness $(\mathrm{r}=0.292$, $\mathrm{P}<0.001)$, and volume $(\mathrm{r}=0.261, \mathrm{P}<0.001)$.

\section{References}

1. Serter S, Ceylan C, Tuncyurek O, Orguc S, Pabuccu Y. Sonographic evaluation of spleen size and prevalence of accessory spleen in a healthy male Turkish population. Turk J Hematol. 2010;27(2):25-8.

2. Niederau C, Sonnenberg A, Muller JE, Erckenbrecht JF, Scholten T, Fritsch W. Sonographic measurement of the normal liver, spleen, pancreas and portal vein. Radiology. 1983;149(1):537-40.

3. DeLand FH. Normal spleen size. Radiology. 1970;97(1):589-92.

4. Alhazmi DA, Mazi OA, Alsulami AM, Abduljabbar AH. Normal size and values in adult population in the western region of Saudi Arabia. Eur J Pharm Med Res. 2017;4(2):166-9.

5. Chakraborti S, Saha N, Debbarma B, Das S, Leishram D. Normal Spleen Length by Ultrasonography in Adults of Tripura. IOSR J Dent Med Sci. 2016;15(1):55-60.

6. Sharma K, Lamichhane PS, Sharma B, Sharma BK. Sonographic Measurement of Spleen in Relation to Age. A Prospective Study among Adult Nepalese People in Western Nepal. J Gandaki Med Coll Nepal. 2017;10(1):11-6.

7. Yadav BK, Sharma LK, Yadav SR, Chakradhar S, Neupane I. sonographic measurements of the spleen in relation to age; a prospective study in eastern Nepalese adults. J Biomed Pharm Res. 2013;2(3):118-21.

8. Arora N, Sharma PK, Sahai A, Singh R. Sonographic measurements of the spleen in relation to age; a prospective study in north Indian adults. J Anat soc India. 2010;59(2):177-81.

9. Gangte SD, Singh NS, Singh MM, Singh WJ. Ultrasonographic Measurement of Splenic Length In Relation To Age of Adult ' $\mathrm{s}$ in Manipur. IOSR J Dent Med Sci. 2015;14(10):43-5.

10. Celiktas M, Ozandac S, Goker P, Bozkir M. Sonographic Determination of Normal Spleen Size in Turkish Adults. IntJ Morphol. 2015;33(4):1401-5.

11. Singh A, Ansari H, Das JK, Chandra N. Ultrasonographic measurement of splenic length in relation with height in Bihari adult population. A prospective study. J Anat Soc India. 2011;60:188-189.

12. Arora N, Sharma PK, Sahai A, Singh R. Sonographic measurement of the spleen: splenic length in adults and its correlation with different parameters. J Anat Soc India. 2013;62:57-61.

13. Siddiqui MA, Ali AHA, Bedewi MA, Serhan OO. Estimation of standard splenic volume in saudi arabian adult population: using 3D reconstruction of abdominal CT scan images. Open Journal of Internal Medicine. 2014;4:7-12.

14. Poddar U, Jagadisan B. Measuring liver and spleen by ultrasonography. Indian Pediatr. 2010;47:475-476.

15. Zhang B, Lewis SM. A study of the reliability of clinical palpation of the spleen. Clin Lab Haematol 1989; 11: 7-10. 
16. Asghar A, Naaz S, Agrawal D. Estimation of standard splenic index (SI) in Indian population: A CT scan based study. Indian Journal of Basic and Applied Medical Research. 2014;3:332-337.

17. Arora N, Sharma PK, Sahai A, Singh R. Sonographic measurements of the spleen in relation to age;A prospective study in North Indian Adults. J Anat Soc India. 2010;59:177-181.

Copyright: () the author(s), 2019. It is an open-access article distributed under the terms of the Creative Commons Attribution License (CC BY 4.0), which permits authors to retain ownership of the copyright for their content, and allow anyone to download, reuse, reprint, modify, distribute and/or copy the content as long as the original authors and source are cited.

How to cite this article: Tekle Y, Hiware SD, Muche A, Tegegne Z, Mohammed H, Bokariya P. Normal Spleen Size in Relation To Weight of Adult Population in the Northwest Ethiopia Region: A Radiological Study. Asian J. Med. Res. 2019;8(1):AT05-AT08.

DOI: dx.doi.org/10.21276/ajmr.2019.8.1.AT2

Source of Support: Nil, Conflict of Interest: None declared. 